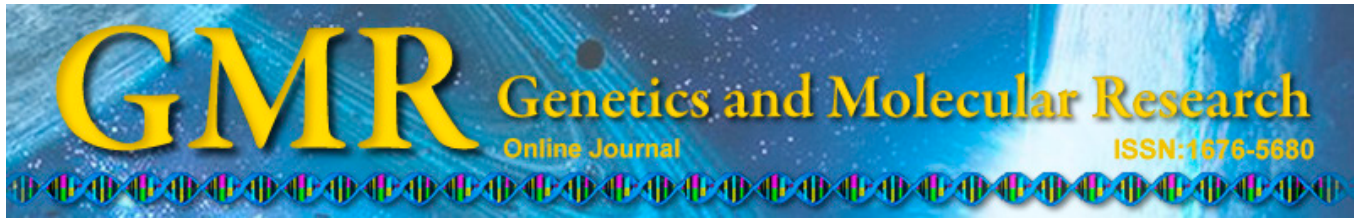

\title{
Random amplified polymorphic DNA analysis of salt-tolerant tobacco mutants generated by gamma radiation
}

\author{
Ö. Çelik and Ç. Atak
}

Department of Molecular Biology and Genetics, Faculty of Science and Letters, Istanbul Kultur University, Ataköy, Istanbul, Turkey

Corresponding author: Ö. Çelik

E-mail: ocelik@iku.edu.tr

Genet. Mol. Res. 14 (1): 1324-1337 (2015)

Received November 5, 2013

Accepted January 24, 2014

Published February 13, 2015

DOI http://dx.doi.org/10.4238/2015.February.13.12

ABSTRACT. Salinity is one of the major problems limiting the yield of agricultural products. Radiation mutagenesis is used to improve salttolerant mutant plants. In this study, we aimed to improve salt-tolerant mutants of two oriental tobacco varieties. One thousand seeds of each variety $\left(\mathrm{M}_{0}\right)$ were irradiated with 100, 200, 300, and 400 Gy gamma rays by $\mathrm{Cs}-137$ gamma. In the $\mathrm{M}_{1}$ generation, 2999 single plants were harvested. The next season, these seeds were bulked and planted to obtain $\mathrm{M}_{2}$ progeny. The seeds of $1900 \mathrm{M}_{2}$ plants were picked separately. Salinity tolerance was tested in the $\mathrm{M}_{3}$ generation. Among $\mathrm{M}_{3}$ plantlets, 10 salt-tolerant tobacco mutants were selected. According to the results of the selection studies, 100- and 200-Gy gamma radiation doses were the effective doses to obtain the desired mutants. Glutathione reductase enzyme activities of salt-tolerant tobacco mutants were determined biochemically as a stress-tolerance marker. The differences between control and salt-tolerant mutants belonging to the Akhisar 97 and İzmir Özbaş tobacco varieties were evaluated by random amplified polymorphic DNA analysis. The total polymorphism rate was $73.91 \%$.

Key words: Mutation breeding; Salt tolerance; Glutathione reductase; Random amplified polymorphic DNA 


\section{INTRODUCTION}

The increase of greenhouse gases that occurs because of industrialization throughout the world triggers changes in environmental conditions. Because of changes in environmental conditions, agricultural production is insufficient and leads to a loss of products. All of the negativities of environmental conditions cause stress in plants. Soil salinity is an important abiotic stress that causes harmful effects on productivity in agricultural areas of the world. Inadequate rainfall and high evaporation in the arid and semi-arid regions are the most important factors that lead to changes in salinity (Kwiatowsky, 1998). Changes in salinity can cause damages such as growth inhibition and decreased leaf numbers and root length (Munns et al., 2006; Moud and Maghsoudi, 2008).

Under salt stress, $\mathrm{Na}^{+}$and $\mathrm{Cl}^{-}$ions enter the hydration layers, such as proteins and amino acids, interact with the non-covalent bonds, and cause conformational changes in proteins (Hirt and Shinozaki, 2004). Decreased chlorophyll and carotenoid contents in leaves, reduced photosynthesis and transpiration, and stomatal closure are important physiological changes that occur in plants under high salt concentrations (Jenks and Hasegawa, 2005). In addition, salinity affects all major events including plant germination, growth, photosynthesis, protein synthesis, energy, and lipid metabolism (Munns et al., 2006). Salinity also causes vacuolization in the leaves, partial swelling in the endoplasmic reticulum, and a decreased number of intercellular spaces, mitochondrial cristae, chloroplasts, and stomata.

Glutathione (GSH) is the tripeptide of glutamate, cysteine, and glycine. It plays an important role in cellular processes and protects cells from environmental stresses. GSH scavenges hydroxyl radicals that are directly produced because of stresses. When reactive oxygen species (ROS) accumulate in the cells, glutathione disulfide (GSSG) and the oxidized disulfide increase to detoxify these radicals. Glutathione reductase (GR) enzyme is a member of the flavin-containing pyridine nucleotide-disulfide oxidoreductase family. This enzyme catalyzes the conversion of GSSG to GSH. In addition to maintaining the antioxidant capacity, a high GSH/GSSG ratio is regulated by this enzyme (Seo et al., 2006).

Ceballos-Picot et al. (1996) indicated that the GSH antioxidant system acts as a marker of oxidative stress in patients with chronic renal failure. Petřivalský et al. (1997) concluded that increases in GR activity could be used as a biochemical marker of oxidative stress in trout liver. Tausz et al. (2004) reported that the GSH system is a stress marker in ecophysiological studies.

Ionizing radiation has a potential use in inducing desirable mutations in agricultural and biological studies to acquire abiotic stress tolerance in plants. The genetic differences that are obtained by ionizing radiation are because of ionization and excitations of the DNA molecule (Esnault et al., 2010). Because of the applied radiation doses and species, different DNA alterations caused by oxidative attacks generate genomic and chromosomal aberrations (Esnault et al., 2010). Therefore, using gamma radiation as a physical mutagen is a possible way to increase genetic variability by increasing the frequency of mutations (Atak et al., 2004; Hewawasam et al., 2004). Researchers tried to improve some important agronomical traits, such as resistance to disease, pathogens, salinity, and drought, using gamma radiation (IAEA, 2009; Esnault et al., 2010; Jain, 2010).

Molecular markers have been widely used to determine the genetic similarities and to characterize variations at the DNA level (Khan et al., 2007). Random amplified polymorphic DNA (RAPD) is the most used marker technique among them. This marker technique shows DNA polymorphisms as differences in the amplification patterns by using random primers. In 
in vitro stress applications, changes at preferential sites can be caused, and RAPD is a suitable method to detect these changes (Zhang et al., 2005; Chen et al., 2006).

In this study, we aimed to select salinity-tolerant mutant plants that were generated by gamma radiation. We used the tobacco plant as a model organism and selected two tobacco varieties that belong to Turkey. The differences between selected salt-tolerant mutants and control plants were screened by RAPD.

\section{MATERIAL AND METHODS}

\section{Plant material and determination of dose}

Tobacco (Nicotiana tabacum L.) is a dicotyledonous plant that has economic and agricultural importance in Turkey. In this study, we used the Akhisar 97 and İzmir Özbaş oriental tobacco varieties, which were taken from the Aegean Agricultural Research Institute. Tobacco varieties that belong to the İzmir region are known for their low nicotine content and compounds containing protein and their high sugar content. The İzmir Özbaş tobacco variety has a mid-tall height, dense leaves (28-48, average 42), and veil-shaped leaves with bulgy and plump edges. This variety is resistant to blue mold and is tolerant to drought. The yield is good and changes according to the soil and climate conditions $(80-150 \mathrm{~kg} / \mathrm{ha})$. The Akhisar 97 tobacco variety has a mid-tall height, and the length of the leaves is independent of the plant height. The leaves of this variety are pale yellow-green, and the average number of leaves is 45. This tobacco variety is resistant to blue mold and drought, like İzmir Özbaş.

We determined the seed water contents as 9\% for Akhisar 97 and 10\% for İzmir Özbaş before the irradiation experiments. Sixty tobacco seeds for each treatment were irradiated with a Cs-137 source in the IBL $437 \mathrm{C}$ irradiation facility belonging to Our Leukemia Children Foundation (dose rate/s $0.09 \mathrm{~Gy}$ ). The gamma radiation doses were 0, 50, 100, 150, 200, 250, $300,400,500$, and $600 \mathrm{~Gy}$. Control and irradiated tobacco seeds were sown in plastic boxes and grown under controlled conditions with a day/night period of $26^{\circ} \mathrm{C} / 18^{\circ} \mathrm{C}(16-\mathrm{h}$ light $/ 8-\mathrm{h}$ dark). In the experiments, each treatment was repeated in triplicate.

Both the $\mathrm{GR}_{50}$, which decreases the fresh weight and dry weight by $50 \%$, and the $\mathrm{LD}_{50}$, which decreases the survival rate by $50 \%$, were determined for each variety by measuring the values of 14-day-old plants.

\section{$M_{1}$ and $M_{2}$ progeny}

One thousand seeds $\left(\mathrm{M}_{0}\right)$ belonging to each variety were irradiated with 100, 200, 300 , and 400 Gy gamma rays using a Cs-137 gamma source. Control and irradiated seeds were planted in seedbeds of Manisa Akhisar Leaf Tobacco Enterprises. One to two months later, the 15-20-cm tobacco seedlings $\left(M_{1}\right)$ were planted in the experimental field belonging to Tobacco Enterprises. Three and a half to four months later, the tobacco seedlings $(15-20 \mathrm{~cm}$ height were planted in the field belonging to Tobacco Enterprises with a spacing of $15 \mathrm{~cm}$ within rows and $40 \mathrm{~cm}$ between rows. Three months after planting the seedlings in the experimental field, 2999 single plants of the $M_{1}$ generation were harvested. The next season, these seeds were bulked and planted in the same field to obtain $M_{2}$ progeny. The seeds of $1900 \mathrm{M}_{2}$ plants were picked separately. 


\section{Salt stress-tolerance analysis}

Germination experiments were carried out under laboratory conditions to evaluate differences in the salinity stress tolerance of the tobacco seeds. Salinity stress experiments were performed under both in vivo and in vitro conditions using 1500 fertile $\mathrm{M}_{3}$ progeny. Seedlings of each variety grown under $250 \mathrm{mM} \mathrm{NaCl}$, which was determined to be the tolerance limit of these varieties in our previous experiments, were selected (Çelik and Atak, 2012).

\section{In vivo salinity tolerance test in $\mathrm{M}_{3}$ progeny}

Completely fertile tobacco $M_{3}$ progeny (1500) were subjected to pre-selection with $250 \mathrm{mM} \mathrm{NaCl}$. For the in vivo salinity tolerance test, seeds were germinated on medium supplemented with Murashige and Skoog (MS) (Murashige and Skoog, 1962) basalt salt, MS vitamins $(0.5 \mathrm{mg} / \mathrm{L}$ pyridoxine $\mathrm{HCl}$ and $0.4 \mathrm{mg} / \mathrm{L}$ thiamine $), 30 \mathrm{~g} / \mathrm{L}$ sucrose, and $8 \mathrm{~g} / \mathrm{L}$ agar. After 3 weeks, the seedlings were sown in perlite and irrigated with quarter-strength Hoagland solution. Salt treatments with 2-month-old seedlings grown in perlite were started by irrigation with quarter-strength Hoagland solution containing $250 \mathrm{mM} \mathrm{NaCl}$, which was determined in the in vitro salinity tolerance test for 14 days (Çelik and Atak, 2012). The seedlings were kept under controlled conditions $\left(16-\mathrm{h} / 8\right.$-h light/dark regime at $\left.27^{\circ} \mathrm{C}\right)$. The mutant plants that showed normal growth like the plants of the control groups were selected and transferred to new pots containing perlite and irrigated with quarter-strength Hoagland solution every day.

\section{In vitro salinity tolerance test in $M_{3}$ progeny}

In vitro salinity tolerance tests were performed for further selection of the mutants. Leaf explants of mutant and control plants were transplanted onto Petri dishes containing callus induction medium. This medium consisted of MS basal salt, modified MS vitamins ( 0.5 $\mathrm{mg} / \mathrm{L}$ pyridoxine $\mathrm{HCl}$ and $0.4 \mathrm{mg} / \mathrm{L}$ thiamine), $30 \mathrm{~g} / \mathrm{L}$ sucrose, $8 \mathrm{~g} / \mathrm{L}$ agar, $2 \mathrm{mg} / \mathrm{L}$ IAA (indole3 -acetic acid), $0.2 \mathrm{mg} / \mathrm{L}$ kinetin, and $250 \mathrm{mM} \mathrm{NaCl}$. For a negative control, the leaf explants of control plants were cultured on callus medium without $\mathrm{NaCl}$. For a positive control, the leaf explants of control plants were cultured on callus medium containing $250 \mathrm{mM} \mathrm{NaCl}$. The callus cultures were maintained in a growth chamber at $27^{\circ} \mathrm{C}$ under a photoperiod of $16 \mathrm{~h}$ of light. Salt-tolerant tobacco mutants were selected according to the appearance of their callus growth with respect to that of the positive and negative controls.

\section{GR (EC. 1.6.4.2) activity assay}

The GR activities of salt-tolerant tobacco mutants were determined according to the method of Foyer and Halliwell (1976). The decrease in oxidized GSH in the presence of reduced nicotinamide adenine dinucleotide phosphate (NADPH) was calculated according to the decreased absorbance at $340 \mathrm{~nm}$ for $1 \mathrm{~min}$. We used the extinction coefficient for GR enzyme, $6.2 \mathrm{mM}^{-1} \cdot \mathrm{cm}^{-1}$ to calculate the GSSG level. One unit of enzyme is equal to the oxidized GSH concentration $(\mathrm{mM})$. The reaction mixture $(1 \mathrm{~mL})$ contained $100 \mathrm{mM}$ phosphate buffer, $\mathrm{pH} 7.8,0.1 \mathrm{mM}$ ethylenediaminetetraacetic acid (EDTA), $0.05 \mathrm{mM}$ NADPH, 3 mM GSSG, and $50 \mu \mathrm{L}$ enzyme extract. The specific enzyme activity was defined as $\mu$ mol $\mathrm{NADPH} \cdot \mathrm{min}^{-1} \cdot \mathrm{mg}^{-1}$ formula weight (Neto et al., 2006; Yazici et al., 2007). 


\section{Genomic DNA isolation and RAPD analysis}

DNA was extracted from the leaves as described by Doyle and Doyle (1987), with some minor modifications. Fresh leaves $(0.05 \mathrm{~g})$ were ground in a mortar by using pestle. The ground material was added to $1 \mathrm{~mL}$ extraction buffer $[2 \%(\mathrm{w} / \mathrm{v})$ cetyltrimethylammonium bromide; $100 \mathrm{mM}$ Tris-Cl buffer, $\mathrm{pH}$ 8.0; 20 mM EDTA, $\mathrm{pH}$ 8.0; $1.4 \mathrm{M} \mathrm{NaCl}$; and 1\% $(\mathrm{w} / \mathrm{v})$ polyvinylpyrrolidone-40]. The samples were incubated at $65^{\circ} \mathrm{C}$ for $90 \mathrm{~min}$, and 500 $\mathrm{mL}$ 24:1 chloroform:isoamyl alcohol ( $\mathrm{v} / \mathrm{v})$ was added to the homogenate and mixed gently. The upper aqueous layer was transferred to a fresh tube containing $600 \mu \mathrm{L}$ isopropanol after centrifugation at $10,000 \mathrm{rpm}$ for $10 \mathrm{~min}$. The mixture was kept at room temperature for 40 min, centrifuged at $5000 \mathrm{rpm}$ for $3 \mathrm{~min}$, and washed twice with $76 \%$ ethanol. The pellets were allowed to sit overnight at room temperature and were resuspended in Tris-EDTA buffer (10

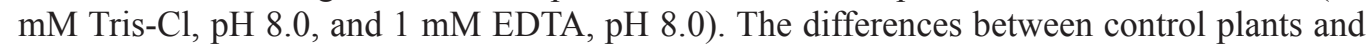
the salt-tolerant mutants of the Akhisar 97 and İzmir Özbaş tobacco varieties were determined by RAPD analysis. The polymerase chain reaction (PCR) analyses were performed according to the method of Williams et al. (1990). Thirteen oligonucleotides with $60 \%$ GC content were synthesized by Operon Technologies, used for RAPD analysis, and given in Table 1. The amplification mixture contained $1 \mathrm{U}$ Taq polymerase, $10 \mu \mathrm{l}$ 10X Taq DNA polymerase buffer, 10 pmol primer, $25 \mathrm{ng}$ genomic DNA, and $1 \mathrm{mM} \mathrm{MgCl}_{2}$ in a total reaction volume of $100 \mu \mathrm{L}$. The amplification was carried out in a Techne (UK) Progene Thermocycler with the following program: 45 cycles of $30 \mathrm{~s}$ at $96^{\circ} \mathrm{C}, 30 \mathrm{~s}$ at $45^{\circ} \mathrm{C}$, and $30 \mathrm{~s}$ at $72^{\circ} \mathrm{C}$. PCR products $(15 \mu \mathrm{L})$ were screened on a $2 \%$ agarose gel.

\begin{tabular}{ll}
\multicolumn{2}{c}{ Table 1. Primer codes and sequences used in RAPD studies. } \\
\hline Primer code & Primer sequence (5'-3') \\
\hline M13 & 5'-GAGGGTGGCGGTTCT-3' \\
B18 & 5'-CCACAGCAGT-3' \\
A & 5'-CAGGCCCTTC-3' \\
A2 & 5'-TGCCGAGCTG-3' \\
A7 & 5'-GAAACGGGG-3' \\
OPB 02 & 5'-TGATCCTGG-3' \\
OPB 05 & 5'-TGCGCCCTTC-3' \\
OPB 06 & 5'-TGCTCTGCCC-3' \\
OPB 08 & 5'-GTCCACACGG-3' \\
OPB 10 & 5'-CTGCTGGGAC-3' \\
OPA 11 & 5'-CAATCGCCGT-3' \\
OPA 14 & 5'-TCTGTGCTGG-3' \\
OPO 04 & 5'-AAGTCCGCTC-3' \\
\hline
\end{tabular}

\section{Genetic distance determination}

RAPD markers were analyzed according to the bands on RAPD gels. The bands were scored as either (1) to indicate the presence or $(0)$ to indicate the absence of bands for each primer. The data were used to calculate approximate levels of polymorphism by dividing the polymorphic bands by the total numbers of scored bands. Common band analysis was conducted using the computer program POPGENE (Yeh et al., 1997) to determine the genetic distance between control plants and salt-tolerant tobacco mutants. The figures for genetic distance were then used as input data for cluster analysis to generate unweighted pair group method with arithmetic mean dendrograms (Nei, 1972). 


\section{Statistical analysis}

Statistical analysis of the data was performed using analysis of variance. We applied the Duncan multiple range test to compare the experimental results of the groups subjected to gamma radiation. For the statistical evaluation of the results, significance was defined by a probability level of $\mathrm{P}<0.05$. Regression analyses were performed to evaluate the relationships between gamma radiation and survival rate, fresh weight, and dry weight (Chew, 1976). All experiments were performed with three replicates. The dendrograms showing the genetic distances between control and mutant plants were analyzed by POPGENE (Yeh et al., 1997).

\section{RESULTS}

\section{Plant material and determination of $\mathrm{GR}_{50}$ and $\mathrm{LD}_{50}$ doses}

The $\mathrm{GR}_{50}$ and $\mathrm{LD}_{50}$ doses were calculated and given in Figure 1. The effects of gamma radiation on the survival rate, fresh weight, and dry weight of the Akhisar 97 and İzmir Özbaş tobacco varieties were given in Figure 1.

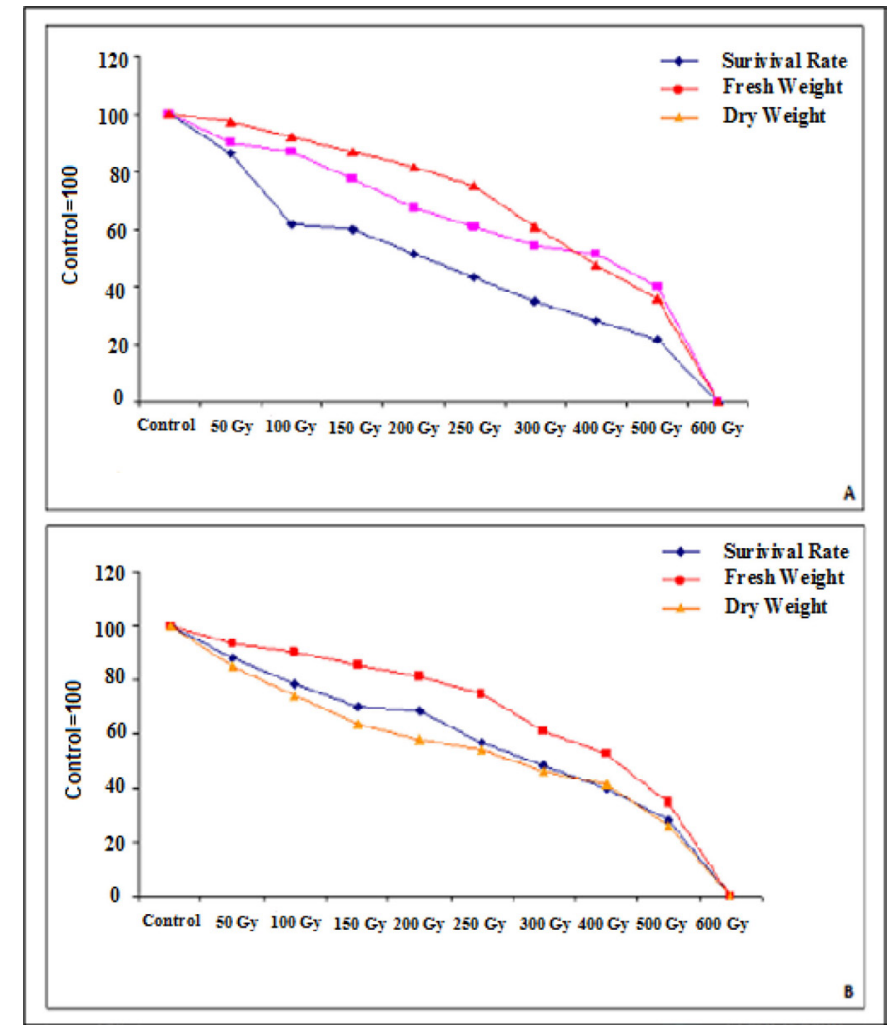

Figure 1. Effects of gamma radiation on survival rate, fresh weight and dry weight in tobacco varieties. $\mathrm{LD}_{50}$ dose for survival rate is $213 \mathrm{~Gy}, \mathrm{GR}_{50}$ doses for fresh and dry weights are 406 and 387 Gy for Akhisar 97 (A) $\mathrm{LD}_{50}$ dose for survival rate is $288 \mathrm{~Gy}, \mathrm{GR}_{50}$ doses for fresh and dry weights are 407 and $268 \mathrm{~Gy}$ for İzmir Özbaş (B) tobacco varieties. 
The relationships between the number of surviving plants, fresh and dry weights, and radiation doses were detected by regression analysis. Regression analysis indicated that the survival rate, fresh weight, and dry weight changed with increasing gamma radiation doses. The radiation doses that were used in the experiment were determined according to survival rates, and the regression curves were given in Figure 2. The Akhisar 97 variety was more radiosensitive than the İzmir Özbaş variety, and the ability of 100-, 200-, 300-, and 400-Gy gamma radiation doses to induce salt-tolerant mutants was determined for both varieties.

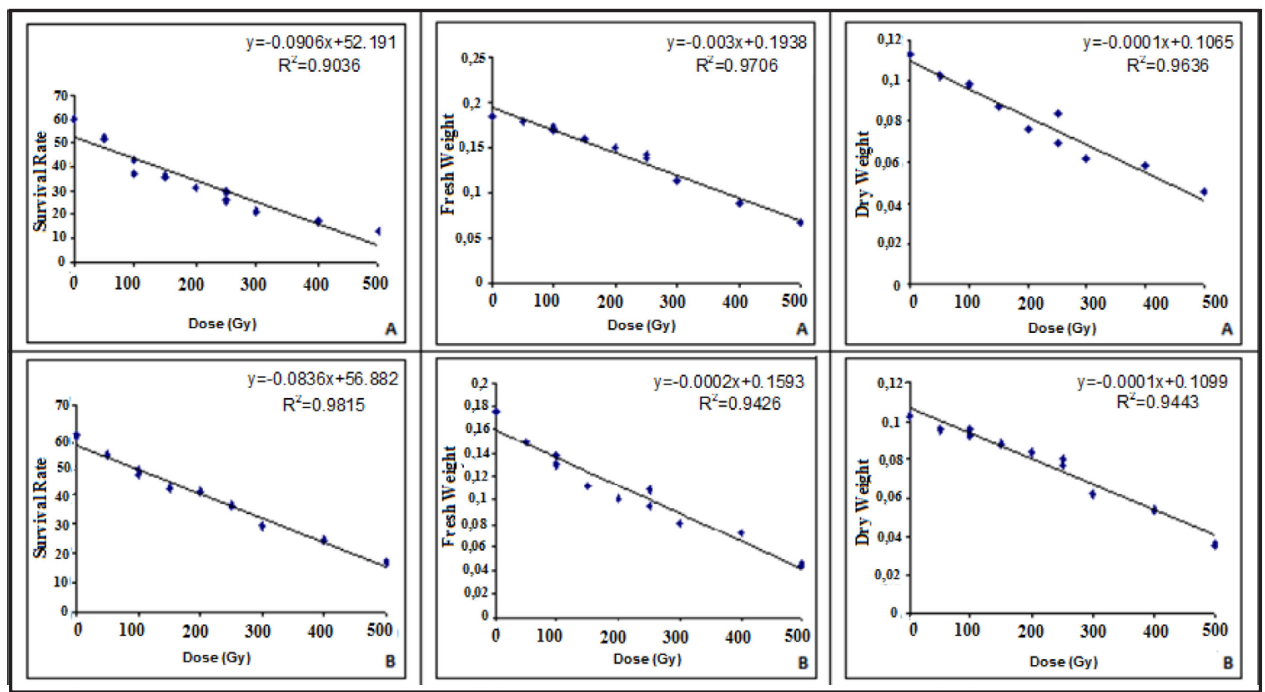

Figure 2. Relationship between survival rate, fresh weight, dry weight, and gamma radiation doses subjected to Akhisar 97 (A) and İzmir Özbaş (B) tobacco varieties.

\section{$M_{1}$ progeny}

The tobacco seeds that were irradiated with $0,100,200,300$, and 400 Gy were sown in seedbeds and transferred to the experimental field. The numbers of seedlings of each variety that were transferred to the field and harvested are given in Table 2.

Table 2. Numbers of irradiated seeds and seedlings transferred to the field and harvested plants to generate $\mathrm{M}_{1}$ generation.

\begin{tabular}{lccc}
\hline Variety & Number of irradiated seeds & Number of transferred seedlings to the field & Number of harvested plants \\
\hline İzmir Özbaş & 1000 & & 775 \\
Control & 1000 & 655 & 570 \\
100 Gy & 1000 & 570 & 519 \\
200 Gy & 1000 & 430 & 418 \\
300 Gy & 1000 & 326 & 290 \\
400 Gy & 1000 & & 875 \\
Akhisar 97 & 1000 & 616 & 580 \\
Control & 1000 & 512 & 486 \\
100 Gy & 1000 & 270 & 195 \\
200 Gy & 1000 & 250 & 85 \\
300 Gy & & & \\
400 Gy & & & \\
\hline
\end{tabular}


With respect to the İzmir Özbaş tobacco variety, $57 \%$ of plants that were grown from irradiated seeds with 200 Gy were transferred to the experimental field. Of the Akhisar 97 variety, $51.2 \%$ of the seedlings that were irradiated with the same dose were transferred. The number of transferred seedlings of this variety decreased at the 300- and 400-Gy gamma radiation doses. When we evaluated the number of harvested plants of both tobacco varieties, we observed decreases that correlated with increasing gamma radiation doses.

\section{$M_{2}$ progeny}

The numbers of plants that were transferred to the field from seedbeds and harvested plants of the $\mathrm{M}_{2}$ population are given in Table 3. We observed decreases in the number of harvested seedlings in both tobacco varieties with increasing gamma radiation doses.

Table 3. Number of seedlings transferred to the field and harvested at $\mathrm{M}_{2}$ plants belonging to İzmir Özbaş and Akhisar 97 tobacco varieties.

\begin{tabular}{lcc}
\hline Variety & Number of transferred seedlings & Number of harvested plants \\
\hline İzmir Özbaş & & \\
Control & 700 & 655 \\
100 Gy & 500 & 405 \\
200 Gy & 410 & 300 \\
300 Gy & 365 & 217 \\
400 Gy & 250 & 68 \\
Akhisar 97 & & \\
Control & 695 & 650 \\
100 Gy & 550 & 455 \\
200 Gy & 440 & 318 \\
300 Gy & 250 & 91 \\
400 Gy & 63 & 18 \\
\hline
\end{tabular}

\section{Selection of salt-tolerant mutants}

At the in vivo selection, 103 of 1500 tobacco plants were determined to be salt tolerant. Forty-two of these plants belonged to the Akhisar 97 variety, and 61 belonged to the İzmir Özbaş tobacco variety. Callus cultures were developed from the leaves of salt-tolerant mutants to perform in vitro selection studies. Ten salt-tolerant tobacco mutants were selected according to the appearance of their callus with respect to those of the positive and negative controls. The codes of the mutants and the radiation doses are given in Table 4 . The callus growth profiles of explants belonging to positive and negative control and mutant plants are shown in Figure 3.

\begin{tabular}{|c|c|}
\hline Plant code & Radiation dose (Gy) \\
\hline Akhisar 97 & \\
\hline 1.1 & 200 \\
\hline 1.3 & 200 \\
\hline 1.10 & 300 \\
\hline 1.11 & 100 \\
\hline 1.17 & 100 \\
\hline İzmir Özbaş & \\
\hline 3.3 & 100 \\
\hline 3.4 & 100 \\
\hline 3.25 & 100 \\
\hline 3.26 & 200 \\
\hline 3.31 & 300 \\
\hline
\end{tabular}



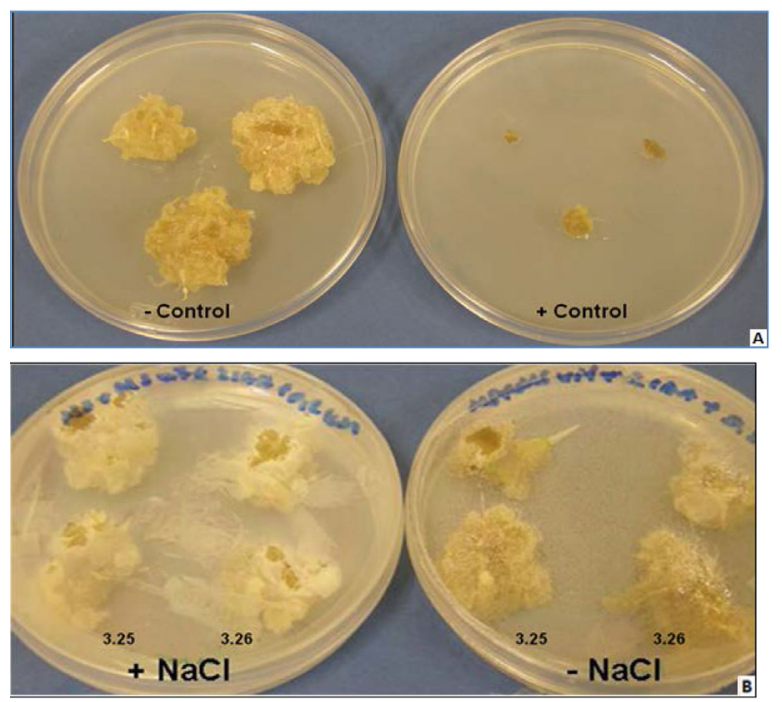

Figure 3. Appearance of callus cultures of explants that belong to positive and negative control plants (A), callus profiles of mutant 1.10 and callus profiles of mutant 3.25 and mutant 3.26 plants in medium containing $\mathrm{NaCl}$ and absence of $\mathrm{NaCl}(\mathbf{B})$.

\section{GR enzyme activities of salt-tolerant mutants}

The GR enzyme activities of mutants that were tolerant to $250 \mathrm{mM}$ salt were biochemically determined, and the activity values are given in Table 5 . While the GR activity of Akhisar 97 control plants was $0.0085 \mu \mathrm{mol} \mathrm{NADPH} \cdot \mathrm{min}^{-1} \cdot \mathrm{mg}^{-1}$ fresh weight, the activities of Akhisar 97 mutants were $0.0303-0.0322 \mu \mathrm{mol} \mathrm{NADPH} \cdot \mathrm{min}^{-1} \cdot \mathrm{mg}^{-1}$ fresh weight. Whereas the GR activity of the İzmir Özbaş control plants was $0.00136 \mu \mathrm{mol} \mathrm{NADPH} \cdot \mathrm{min}^{-1} \cdot \mathrm{mg}^{-1}$ fresh weight, the activities of mutants were $0.0320-0.0411 \mu \mathrm{mol} \mathrm{NADPH} \cdot \mathrm{min}^{-1} \cdot \mathrm{mg}^{-1}$ fresh weight. The highest GR activities were found for mutants 1.3 and 3.25, which belonged to the Akhisar 97 and İzmir Özbaş tobacco varieties, respectively.

Table 5. Glutathione reductase enzyme activities of $250 \mathrm{mM} \mathrm{NaCl}$ tolerant mutant plants belonging to Akhisar 97 ve İzmir Özbaş varieties.

\begin{tabular}{lc}
\hline Plant code & GR activity $\left(\mu \mathrm{mol} \mathrm{NADPH} \cdot \mathrm{min}^{-1} \cdot \mathrm{mg}^{-1}\right.$ fresh weight $) \pm \mathrm{SD}$ \\
\hline Akhisar 97 & \\
Control & $0.0085 \pm 0.0027^{\mathrm{a}}$ \\
1.1 & $0.0314 \pm 0.0035^{\mathrm{b}}$ \\
1.3 & $0.0322 \pm 0.0110^{\mathrm{c}}$ \\
1.10 & $0.0316 \pm 0.0180^{\mathrm{d}}$ \\
1.11 & $0.0303 \pm 0.0150^{\mathrm{e}}$ \\
1.17 & $0.0318 \pm 0.0040^{\mathrm{d}}$ \\
İzmir Özbaş & \\
Control & $0.0013 \pm 0.00041^{\mathrm{a}}$ \\
3.3 & $0.0320 \pm 0.0032^{\mathrm{b}}$ \\
3.4 & $0.0346 \pm 0.0170^{\mathrm{c}}$ \\
3.25 & $0.0411 \pm 0.0160^{\mathrm{d}}$ \\
3.26 & $0.0384 \pm 0.0041^{\mathrm{e}}$ \\
3.31 & $0.0405 \pm 0.0130^{\mathrm{d}}$ \\
\hline
\end{tabular}




\section{RAPD analysis}

In this research, the differences caused by gamma radiation among the control plants and the mutants were examined using RAPD markers. Five of 13 random primers were chosen for further amplification of DNA and RAPD analysis (M13, A7, OPB 02, OPB 05, and OPB 08). Control plants, which did not receive gamma radiation treatment, showed amplification with all five primers. Twenty-three DNA bands were amplified from both varieties. Some of the RAPD bands were monomorphic, while some of them showed at least one polymorphism (Figure 4). We observed 17 polymorphic bands that were amplified by five primers.
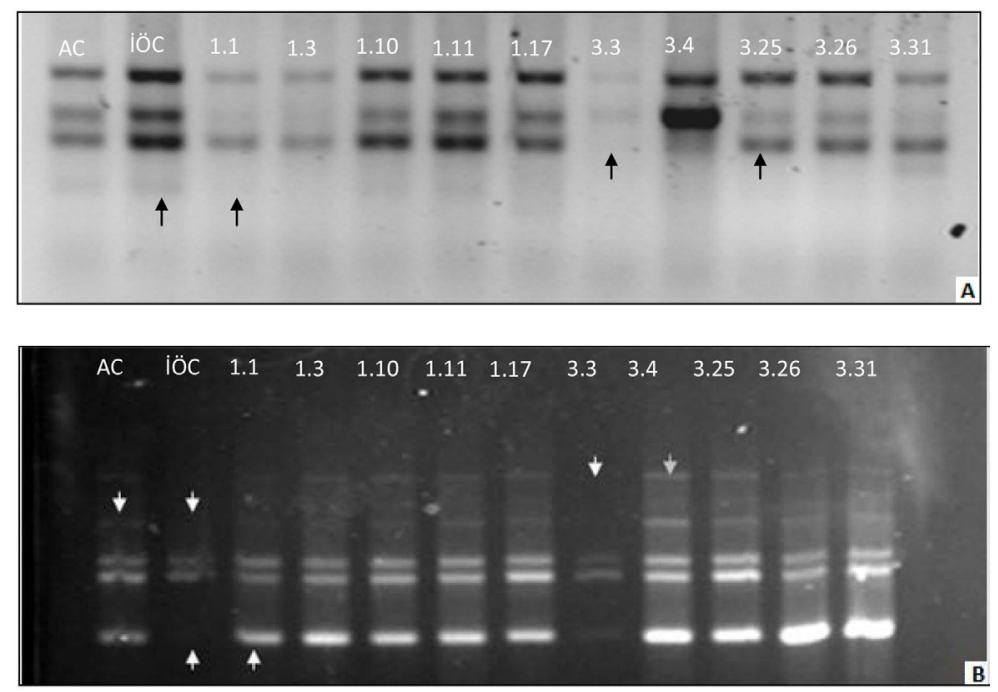

Figure 4. RAPD profiles among salt-tolerant mutants and control samples of Akhisar 97 and İzmir Özbaş tobacco varieties. A. Polymorphic bands obtained by the A7 primer. B. Polymorphic bands obtained by the OPB08 primer. Polymorphic bands are indicated by arrows.

The average polymorphism rate was calculated by determining the number of polymorphic bands relative to the total number of bands and is given in Table 6 . We found that the total polymorphism rate was $73.91 \%$ with these five primers.

Table 6. Numbers of amplified products, polymorphic bands and polymorphism rates.

\begin{tabular}{lccc}
\hline Primer & Number of bands & Number of polymorphic bands & Polymorphism rate (\%) \\
\hline M13 & 4 & 3 & 75.0 \\
OPB 02 & 6 & 6 & 100.0 \\
A7 & 4 & 2 & 50.0 \\
OPB 05 & 4 & 3 & 75.0 \\
OPB 08 & 5 & 3 & 60.0 \\
Total & 23 & 17 & 73.91 \\
\hline
\end{tabular}

Using the RAPD data, we calculated the distances between salt-tolerant mutants and control individuals of these two tobacco varieties (Table 7). A dendrogram was constructed using POPGENE and is illustrated in Figure 5. 
Table 7. Nei’s genetic distance (below diagonal) among salt-tolerant mutants of Akhisar 97(A), İzmir Özbaş (IÖ) and control samples.

\begin{tabular}{|c|c|c|c|c|c|c|c|c|c|c|c|c|}
\hline & A (control) & İ̈ (control) & 1.1 & 1.3 & 1.10 & 1.11 & 1.17 & 3.3 & 3.4 & 3.25 & 3.26 & 3.31 \\
\hline A (control) & 1.00 & & & & & & & & & & & \\
\hline İÖ (control) & 0.33 & 1.00 & & & & & & & & & & \\
\hline 1.1 & 0.33 & 0.40 & 0.00 & & & & & & & & & \\
\hline 1.3 & 0.33 & 0.40 & 0.00 & 0.00 & & & & & & & & \\
\hline 1.10 & 0.33 & 0.40 & 0.00 & 0.00 & 0.00 & & & & & & & \\
\hline 1.11 & 0.35 & 0.33 & 0.25 & 0.25 & 0.25 & 0.00 & & & & & & \\
\hline 1.17 & 0.23 & 0.36 & 0.36 & 0.36 & 0.30 & 0.30 & 0.00 & & & & & \\
\hline 3.3 & 0.52 & 0.25 & 0.44 & 0.44 & 0.44 & 0.37 & 0.37 & 0.00 & & & & \\
\hline 3.4 & 0.36 & 0.43 & 0.35 & 0.35 & 0.35 & 0.29 & 0.29 & 0.29 & 0.00 & & & \\
\hline 3.25 & 0.33 & 0.39 & 0.32 & 0.32 & 0.32 & 0.18 & 0.18 & 0.43 & 0.27 & 0.00 & & \\
\hline 3.26 & 0.33 & 0.39 & 0.32 & 0.32 & 0.32 & 0.10 & 0.10 & 0.43 & 0.35 & 0.09 & 0.00 & \\
\hline 3.31 & 0.35 & 0.33 & 0.25 & 0.25 & 0.25 & 0.25 & 0.25 & 0.18 & 0.20 & 0.22 & 0.22 & 0.00 \\
\hline
\end{tabular}

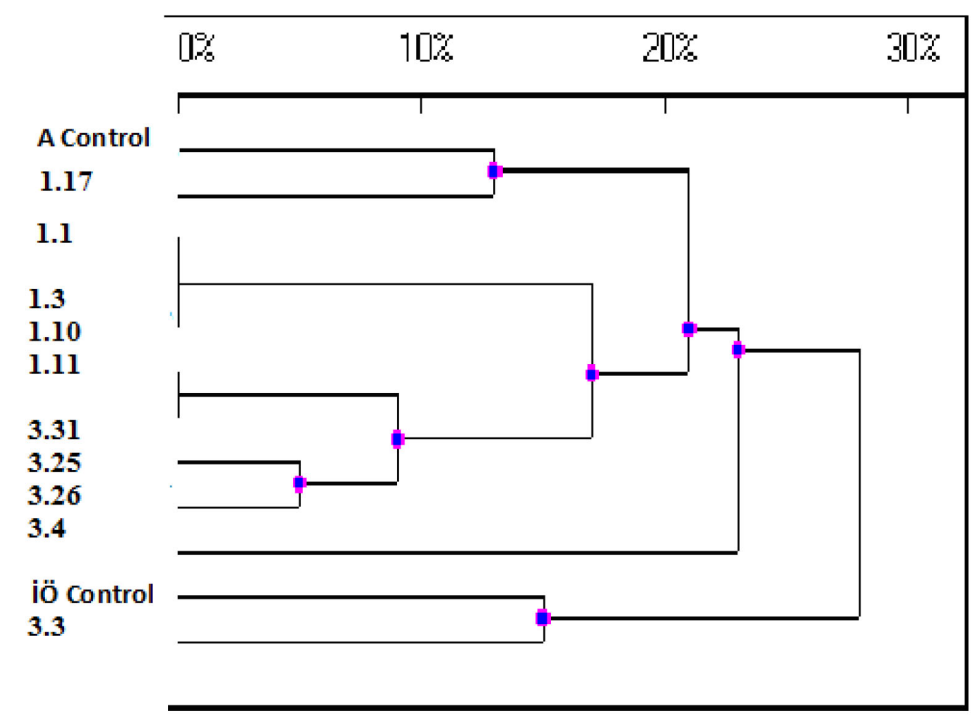

Figure 5. UPGMA dendrogram showing the relationships between salt-tolerant mutants and control samples of Akhisar 97(A) and İzmir Özbaş (İÖ) varieties.

The genetic distance between the salt-tolerant mutants 1.1, 1.3, and 1.10 and the Akhisar 97 control plant was 33\%. Genetic distances of 35 and 23\% were observed between mutants 1.11 and 1.17 and their control plant. The genetic distances between the İzmir Özbaş control plant and salt-tolerant mutants $3.3,3.4,3.25,3.26$, and 3.31 were $25,43,39,39$, and $33 \%$, respectively.

\section{DISCUSSION}

Salinity stress causes changes in biochemical and physiological mechanisms of plants. Agricultural yield losses due to the environmental problem are an important issue (Babaeian et al., 2011; Wang and Frei, 2011). Salinity tolerance mechanisms are low- or high-complexity mechanisms. Low-complexity mechanisms include changes in different biochemical 
pathways. Important processes like photosynthesis and respiration, cytoskeleton and cell wall dynamics, interactions between the plasma membrane and cell wall, DNA methylation, structural changes of chromosomes and chromatin, polyploidization, and DNA elimination are controlled by high-complexity mechanisms. It is believed that the protection of highcomplexity mechanisms is under the coordinated control of low-complexity mechanisms. The genes that are responsible for compensating for stress or that encode the effectors are important in the adaptation process (Jenks and Hasegawa, 2005).

In this study, we aimed to contribute to the solution of this serious problem. For this purpose, we used two oriental tobacco varieties as model organisms in radiation studies to induce genetic variability and selected salt-tolerant mutants. According to our studies, the $\mathrm{LD}_{50}$ dose was 213 Gy for Akhisar 97 and 288 Gy for İzmir Özbaş; therefore, Akhisar 97 was more sensitive to radiation than İzmir Özbaş.

Wada et al. (1998) investigated the underlying mechanism of differential radiosensitivity in two tobacco varieties using up to 500 Gy gamma radiation. Briggs and Constantin (1977) reported that the dose range between 250 and $300 \mathrm{~Gy}$ is the effective dose for tobacco plants.

In field experiments, the number of harvested plants decreased according to the level of damage caused by gamma radiation. Consequently, we observed decreased seedling and harvested plant numbers in $\mathrm{M}_{1}$ and $\mathrm{M}_{2}$ generations with increasing gamma radiation doses.

Mutants in the $\mathrm{M}_{3}$ population of both varieties were selected that were tolerant to 250 $\mathrm{mM} \mathrm{NaCl}$. We chose 10 salt-tolerant mutants, including five mutants from each variety, from the irradiated tobacco varieties after in vivo and in vitro selection studies.

The ascorbate-GSH cycle is an important step in the detoxification of ROS (Eltelib et al., 2012). To examine the activity of GR in mutant plants, we measured the enzyme activity in the control plants and salt-tolerant tobacco mutants. We determined that all NaCl-tolerant tobacco plants had increased GR activity. In our previous study, we compared the differences between in vitro and in vivo salt-stress experimental conditions for tobacco plants. GR was the only antioxidant enzyme that showed a statistically significant difference between the two conditions (Çelik and Atak, 2012). To support our results, Hernández et al. (2000) reported that $\mathrm{NaCl}$-tolerant pea plants showed higher GR activities than sensitive pea plants.

In mutation-breeding studies, the main aim is to improve the plant characteristics by protecting the mother plant's features. Thus, molecular marker analysis is important to screen the genetic differences (Ahloowalia and Maluszynski, 2001; Patade et al., 2006). The RAPD technique is a useful molecular method for genetic fingerprinting that requires only a small amount of DNA and random primers; sequence knowledge and the use of radioactive isotopes or hybridization protocols are not needed. In addition, the easy and fast application makes RAPD advantageous for molecular analyses (Khan et al., 2009). RAPD marker analysis is a suitable method to detect DNA alterations caused by radiation treatments. It has been used widely to determine genetic variabilities in mutant plants (Atak et al., 2011; Dhakshanamoorthy et al., 2011; Girija et al., 2013).

In this research, DNA fingerprints of the 10 selected salt-tolerant tobacco plants were determined by RAPD using five random primers. Of the Akhisar 97 mutants, two were irradiated with $100 \mathrm{~Gy}$, two were irradiated with $200 \mathrm{~Gy}$, and one was irradiated with $300 \mathrm{~Gy}$. Of the salt-tolerant İzmir Özbaş mutants, three were irradiated with $100 \mathrm{~Gy}$, one was irradiated with $200 \mathrm{~Gy}$, and one was irradiated with 300 Gy. The 100- and 200-Gy gamma radiation doses were the effective doses to obtain the desired mutants. The total polymorphism rate with these five primers was $73.91 \%$, and two salt-tolerant mutants that were separated by a long genetic 
distance were irradiated with 100 Gy gamma radiation.

Polymorphisms were detected by the randomly primed PCRs. The disappearance of the control bands and the appearance of new bands were observed in the plants subjected to gamma radiation relative to the control plants. The loss of the bands may be related to singleand double-strand breaks, modified bases, oxidized bases, and point mutations induced by gamma radiation (Esnault et al., 2010). The appearance of new bands may indicate changes in some oligonucleotide priming sites due to mutations or conformational DNA changes (Dhakshanamoorthy et al., 2011).

In conclusion, 10 salt-tolerant mutants were acquired using various doses of gamma radiation. The mutants were analyzed biochemically, and the differences between the mutants and their control plants were analyzed using the RAPD method. The genetic differences between these mutants and controls will be shown by advanced molecular biology techniques, and the salt-tolerance mechanisms of the mutants will be identified in future studies.

\section{ACKNOWLEDGMENTS}

Research carried out at the Istanbul University Institute of Science and Engineering, with the title "Induce of salt tolerance tobacco (Nicotiana tabacum L.) by gamma radiation and selection of mutants" (Ph.D. thesis) and was supported by the Research Fund of Istanbul University (Project \#T2130). The authors also thank Mehmet Ali Baki at Tekel Leaf Tobacco Enterprises, Akhisar, Manisa, Turkey, for allowing the field studies of two oriental tobacco varieties.

\section{REFERENCES}

Ahloowalia BS and Maluszynski M (2001). Induced mutations - a new paradigm in plant breeding. Euphytica 118: 167-173. Atak Ç, Alikamanoglu S, Acik L and Canbolat Y (2004). Induced of plastid mutations in soybean plant (Glycine max L. Merrill) with gamma radiation and determination with RAPD. Mutat. Res. 556: 35-44.

Atak Ç, Çelik Ö and Açik L (2011). Genetic analysis of Rhododendron mutants using random amplified polymorphic DNA (RAPD). Pak. J. Bot. 43: 1173-1182.

Babaeian M, Esmaeilian Y, Tavassoli A and Asgharzade A (2011). The effects of water stress, manure and chemical fertilizer on grain yield and grain nutrient content in barley. Sci. Res. Essays 6: 3697-3701.

Briggs RW and Constantin MJ (1977). Radiation Types and Radiation Sources. Manual on Mutation Breeding. Technical Reports Series N: 19, International Atomic Energy Agency, Vienna, 7-20.

Ceballos-Picot I, Witko-Sarsat V, Merad-Boudia M, Nguyen AT, et al. (1996). Glutathione antioxidant system as a marker of oxidative stress in chronic renal failure. Free Radic. Biol. Med. 21: 845-853.

Chen G, Zhao YW, Jia JF, Wang YH, et al. (2006). Physiological and biochemical characteristics and molecular-biological identification of a gigantic tobacco mutant. Zhi Wu Sheng Li Yu Fen. Zi. Sheng Wu Xue Xue Bao 32: 24-30.

Chew V (1976). Uses and abuses of Duncan's multiple range test. Proc. Fla. State Hort. Soc. 89: 251-253.

Çelik Ö and Atak Ç (2012). The effect of salt stress on antioxidative enzymes and proline content of two Turkish tobacco varieties. Turk. J. Biol. 36: 339-356.

Dhakshanamoorthy D, Selvaraj R and Chidambaram AL (2011). Induced mutagenesis in Jatropha curcas L. using gamma rays and detection of DNA polymorphism through RAPD marker. C R Biol. 334: 24-30.

Doyle JJ and Doyle JL (1987). A rapid DNA isolation procedure for small quantities of fresh leaf tissue. Phytochem. Bull. 19: 11-15.

Eltelib HA, Fujikawa Y and Esaka M (2012). Overexpression of the acerola (Malpighia glabra) monodehydroascorbate reductase gene in transgenic tobacco plants results in increased ascorbate levels and enhanced tolerance to salt stress. S. Afr. J. Bot. 78: 295-301.

Esnault MA, Legue F and Chenal C (2010). Ionizing radiation: advances in plant response. Environ. Exp. Bot. 68: 231-237.

Foyer CH and Halliwell B (1976). The presence of glutathione and glutathione reductase in chloroplasts: A proposed role in ascorbic acid metabolism. Planta 133: 21-25. 
Girija M, Gnanamurthy S and Dhanavel D (2013). Genetic diversity analysis of cowpea mutant (Vigna unguiculata (L.) Walp) as revealed by RAPD marker. Int. J. Adv. Res. 1: 139-147.

Hernández JA, Jiménez A, Mullineaux P and Sevilla F (2000). Tolerance of pea (Pisum sativum L.) to long-term salt stress is associated with induction of antioxidant defences. Plant Cell Environ. 23: 853-862.

Hewawasam WDCJ, Bandara DC and Aberathne WM (2004). New phenotypes of Crossandra infundibuliformis var. Danica through in vitro culture and induced mutations. Trop. Agric. Res. 16: 253-270.

Hirt H and Shinozaki K (2004). Topics in Current Genetics: Plant Responses to Abiotic Stress. Springer, Berlin.

IAEA (2009). International Atomic Energy Agency Nuclear Technology Review. Available at [http://www.iaea.org/ Publications/Reports/ntr2009.pdf], Vienna.

Jain SM (2010). Mutagenesis in crop improvement under the climate change. Rom. Biotech. Lett. 15: 88-106.

Jenks M and Hasegawa PM (2005). Plant Abiotic Stress (Roberts JA, ed.). Blackwell Publishing, Oxford, 1-14.

Khan IA, Dahot MU and Khatri A (2007). Study of genetic variability in sugarcane induced through mutation breeding. Pak. J. Bot. 39: 1489-1501.

Khan MA, von Witzke-Ehbrecht S, Maass BL and Becker HC (2009). Relationships among different geographical groups, agro-morphology, fatty acid composition and RAPD marker diversity in safflower (Carthamus tinctorius). Genet. Resour. Crop Ev. 56: 19-30.

Kwiatowsky J (1998). Food and Rural Development and Agriculture and Agrifood. Salinity Classification, Mapping and Management, Alberta.

Moud AM and Maghsoudi K (2008). Salt stress effects on respiration and growth of germinated seeds of different wheat (Triticum aestivum L.) cultivars. World J. Agric. Sci. 4: 351-358.

Munns R, James RA and Lauchli A (2006). Approaches to increasing the salt tolerance of wheat and other cereals. J. Exp. Bot. 57: 1025-1043.

Murashige T and Skoog F (1962). A revised medium for rapid growth and bio assays with tobacco tissue cultures. Physiol. Plant. 15: 473-497.

Nei M (1972). Genetic distance between populations. Am. Nat.106: 283-292.

Neto ADA, Prisco JT, Enéas-Filho J and Abreu CEB (2006). Effect of salt stress on antioxidative enzymes and lipid peroxidation in leaves and roots of salt-tolerant and salt-sensitive maize genotypes. Environ. Exp. Bot. 56: 87-94.

Patade VY, Suprasanna P, Bapat VA and Kulkarni UG (2006). Selection for abiotic (salinity and drought) stress tolerance and molecular characterization of tolerant lines in sugarcane. Bhabha Atom. Res. Cent. News 273: 244-256.

Petřivalský M, Machala M, Nezveda K and Piačka V (1997). Glutathione-dependent detoxifying enzymes in rainbow trout liver: search for specific biochemical markers of chemical stress. Environ. Toxicol. Chem. 16: 1417-1421.

Seo JS, Lee KW, Rhee JS, Hwang DS, et al. (2006). Environmental stressors (salinity, heavy metals, $\mathrm{H}_{2} \mathrm{O}_{2}$ ) modulate expression of glutathione reductase (GR) gene from the intertidal copepod Tigriopus japonicus. Aquat Toxicol. 80: 281-289.

Tausz M, Šircelj H and Grill D (2004). The glutathione system as a stress marker in plant ecophysiology: is a stressresponse concept valid? J. Exp. Bot. 55: 1955-1962.

Wada H, Koshiba T, Matsui T and Sato M (1998). Involvement of peroxidase in differential sensitivity to $\gamma$-radiation in seedlings of two Nicotiana species. Plant Sci. 132: 109-119.

Wang Y and Frei M (2011). Stressed food - the impact of abiotic environmental stresses on crop quality. Agric. Ecosys. Environ. 141: 271-286.

Williams JG, Kubelik AR, Livak KJ, Rafalski JA, et al. (1990). DNA polymorphisms amplified by arbitrary primers are useful as genetic markers. Nucleic Acids Res. 18: 6531-6535.

Yazici I, Türkan I, Sekmen AH and Demiral T (2007). Salinity tolerance of purslane (Portulaca oleracea L.) is achieved by enhanced antioxidative system, lower level of lipid peroxidation and proline accumulation. Environ. Exp. Bot. 61: 49-57.

Yeh FC, Yang RC, Boyle TBJ and Ye ZH (1997). Popgene: The User Friendly Shareware for Population Genetic Analysis. Molecular Biology and Biotechnology Centre, University of Alberta, Calgary.

Zhang HY, Liu XZ, He CS and Zheng CM (2005). Random amplified DNA polymorphism of Nicotiana tabacum L. cultivars. Biol. Plant. 49: 605-607. 